\title{
Effect of Video-assisted Teaching on Knowledge of Staff Nurses regarding Lamaze Breathing Exercises during the First Stage of Labour to Improve Maternal and Foetal Outcome among Primi Parturient Mothers
}

\author{
Sharda Nagvanshi', Linson CC $^{2}$ \\ ${ }^{1}$ RKDF College of Nursing, Bhopal, Madhya Pradesh, India. \\ ${ }^{2} \mathrm{JOSCO}$, Mangalore. \\ DOI: https://doi.org/10.24321/2348.2133.202006
}

\section{I $\quad \mathbf{N} \quad \mathbf{F} \quad \mathbf{O}$}

\section{Corresponding Author:}

Sharda Nagvanshi, RKDF College of Nursing, Bhopal, Madhya Pradesh, India

E-mail Id:

shardanagvanshi@gmail.com

Orcid Id:

https://orcid.org/0000-0001-7269-0248

How to cite this article:

Nagvanshi S, Linson CC. Effect of Video-assisted Teaching on Knowledge of Staff Nurses regarding Lamaze Breathing Exercises during the First Stage of Labour to Improve Maternal and Foetal Outcome among Primi Parturient Mothers. Ind J Holist Nurs 2020; 11(4): 12-18.

Date of Submission: 2020-12-05

Date of Acceptance: 2020-12-28
$\begin{array}{llllllll}\mathbf{A} & \mathbf{B} & \mathbf{S} & \mathbf{T} & \mathbf{R} & \mathbf{A} & \mathbf{C} & \mathbf{T}\end{array}$

Background: The present study was conducted to assess the impact of video aided teaching on knowledge gain of staff nurses regarding lamaze breathing exercises throughout the first stage of labour.

Method: An experimental research design was chosen with pre-test and post-test of experimental and control group. The sample size was sixty registered staff nurses divided into two groups, thirty in experimental and thirty in control group. The tools used for conducting the study included demographic data and a self structured questionnaire to assess knowledge of experimental and control group. The experimental group was given video assisted teaching as an intervention and the control group was used for comparison without intervention.

Result: The data were analysed with the help of descriptive and inferential statistics. The study clearly shows that there was a significant gain in knowledge of staff nurses of the experimental group with video assisted teaching that emphasises the lamaze breathing exercises during first stage of labour are safe measures to enhance maternal and foetal outcomes.

Conclusion: The staff nurses are benefited with video assisted teaching to enhance knowledge and they can use the breathing exercises during first stage of labour to promote comfort to labouring women and also minimise the use of medication and risk of LSCS during labour.

Keywords: Lamaze Breathing Exercise, Video Assisted Teaching, Maternal and Foetal Outcome, Primi Parturient Mothers 


\section{Introduction}

Pregnant women commonly worry about the pain they will experience during labour and childbirth. Labour pain is one of the severest pains. Controlling labour pain is a major concern of maternity care especially those who experience labour and delivery for the first time definitely would have some sort of fear about the outcome of delivery. ${ }^{1}$ Nonpharmacological methods may be helpful for promoting comforts during labour without side effects. In India, pregnant women in general and first-time mothers, in particular, require a vast amount of information. ${ }^{2}$ The lamaze - a childbirth education method teaches that birth is a normal, natural, and healthy process and the woman should be empowered to approach it with confidence. It is also known as a method of "psycho prophylaxis". The Lamaze method of childbirth includes a set of breathing exercises and we teach these exercises to antenatal mothers. The expectant mother is prepared psychologically and physically to give birth without pain-relieving drugs with the help of these breathing exercises ${ }^{3}$

The aim of Lamaze classes is to encourage women to recognize their innate abilities to cope successfully with the challenges of labour and birth in any setting and to help them to have a stress free and safe delivery. It is an effective non-invasive, non-pharmacologic, supportive education for reducing labour pain and improving the behavioural responses of women in labour. ${ }^{4}$

Lamaze breathing techniques are based on the idea that controlled breathing can enhance relaxation and decrease the perception of pain. Some of the important techniques for controlled breathing include: ${ }^{5}$

- Slow, deep breathing

- Maintaining a rhythm

- Breathing through your mouth or nose

- Keeping your eyes open or closed

- Focusing on one simple physical item, such as a photograph or your partner

\section{Instructions given to Labouring Mothers when Contractions Begin ${ }^{6}$}

To take a deep breath at the beginning and end of each contraction. This is often referred to as a cleansing or relaxing breath.

\section{During the First Stage of Labour}

1. Start with a slow deep breath as contraction starts and then slowly breathe out, releasing all physical tension from head to toes. This is often referred to as an organizing breath.

2. Slowly inhale through the nose then pause and exhale slowly through your mouth.

3. Each time when labouring women exhale, they are taught to focus on relaxing a different body part.

\section{During Active Labour}

1. Start with an organizing breath.

2. Breathe in through the nose and out through the mouth.

3. Keep breathing as slow as possible, but speed it up as the intensity of the contraction increases.

4. Relax the shoulders.

5. As the contraction peaks and breathing rate increases, switch to light breathing both in and out through the mouth about one breath per second.

6. As the intensity of the contraction decreases, slow the breathing and go back to breathing in with the nose and out with the mouth.

\section{Transition Breathing}

As the labouring mothers switch to light breathing during active labour (step 5 above), transition breathing can help control feelings of despair and exhaustion.

- Take an organizing breath

- Focus attention on one thing - a picture, your partner, even a spot on the wall

- During a contraction, breath in and out through the mouth at a rate of 1 to 10 breaths every 5 seconds

- Every fourth or fifth breath, blow out a longer breath

- When the contraction is over, take a relaxing breath

If needed, they can verbalize transition breathing with a "hee" for each of the shorter breaths and a "hoo" for the longer breath.

\section{Problem Statement}

Effect of Video-assisted teaching on Knowledge of Staff Nurses regarding Lamaze Breathing Exercises during the First Stage of Labour to improve Maternal and Foetal Outcome among Primi Parturient Mothers at Selected Hospitals at Bhopal, (M.P.).

\section{Objectives of the Study}

- Assess the knowledge score of staff nurses in the experimental group and control group on Lamaze breathing exercises during the first stage of labour to improve maternal and Foetal outcome among primi parturient mothers.

- Develop a video-assisted teaching (VAT) program on Lamaze breathing exercises during the first stage of labour to improve maternal and Foetal outcome among primi parturient mothers during the first stage of labour.

- Assess the effects of video-assisted teaching (VAT) on the experimental group regarding knowledge gain on Lamaze breathing exercises during the first stage of labour to improve maternal and foetal outcome among primi parturient mothers. 
- Compare the knowledge of experimental and control group regarding Lamaze breathing exercises during the first stage of labour to improve maternal and foetal outcome among primi parturient mothers

- Associate the pre-interventional level of knowledge of experimental and control group with their selected demographic variables.

\section{Null Hypothesis}

$\mathbf{H}_{\mathbf{1}}$ : There will be no significant difference between the knowledge score of the staff nurses of the experimental group with video-assisted teaching on Lamaze breathing exercises during the first stage of labour to improve maternal and foetal outcome among primi parturient mothers.

$\mathbf{H}_{\mathbf{2}}$ : There will be no significant difference between the knowledge of the control and experimental group after video-assisted teaching is provided to the experimental group regarding Lamaze breathing exercises during the first stage of labour to improve maternal and foetal outcome among primi parturient mothers.

$\mathbf{H}_{3}$ : There will be no significant association between the experimental and control group with their selected demographic variables on the gain of knowledge regarding Lamaze breathing.

\section{Research Methodology}

The research approach adopted in the study was an evaluative one to assess the effect of video-assisted teaching on the knowledge of staff nurses with Lamaze breathing exercises during the first stage of labour to improve maternal and foetal outcome among primi parturient mothers.

\section{Research Design}

A true experimental research design with pre-test and posttest of experimental and control group was used.

\section{Variables under Study}

Independent Variable: The video-assisted teaching on Lamaze breathing exercises.

Dependent Variable: Knowledge is a dependent variable, dependent on video-assisted teaching.

\section{Demographic Variables}

Age, educational qualification, professional experience, clinical experience in obstetric and gynaecological nursing wards, previous exposure to non-pharmacological interventions during labour and source of information about Lamaze breathing exercises.

\section{Setting}

The study was conducted at RKDF Medical College, Hospital \& Research Center, Bhopal. It is one of the teaching hospitals of Bhopal district in Madhya Pradesh. The hospital consists of 1000 beds in total and 65 beds are in maternity wards.

\section{Sample}

The samples were 60 staff nurses who fulfilled the inclusion criteria out of that 30 were taken in the experimental group $\& 30$ were taken as control group.

\section{Criteria for Sample Selection}

\section{Inclusion Criteria}

- Staff nurses present at the time of data collection

- Staff nurses working in the selected hospitals

- Staff nurses willing to participate in the study

\section{Exclusion Criteria}

- $\quad$ Staff nurses who were not willing to participate in the study

- Staff nurses with a post-graduate degree in the obstetrical and gynaecological nursing department

- Auxiliary nurses and midwives were not included

\section{Sampling}

In this study, a total of 60 staff nurses were selected by simple random sampling technique.

\section{Duration of Study}

6 weeks.

\section{Development and Description of the Tool}

The following steps were used for the preparation of the tool:

- By extensive review of literature from books, journals, manuals; reports and published researches, newspapers and internet

- Consultation with experts

- Testing reliability and validity for correction and modification of the tools

Section A: Demographic variables

Section B: Self-constructed questionnaire with thirty items to assess the knowledge of staff nurses on Lamaze breathing exercises during the first stage of labour.

Section C: Preparation of video-assisted teaching on Lamaze breathing exercises during the first stage of labour for intervention on the experimental group.

\section{Scoring Procedure}

Each question had four options from which the sample had to choose one correct answer. The right answer was scored as one and the wrong option was scored as zero. The scoring was interpreted as below:

- Inadequate knowledge - score less than $50 \%$

- Moderate knowledge - score between 51-75\%

- Adequate knowledge - more than $75 \%$

\section{Intervention}

The video-assisted teaching programme of 45 minutes 
duration was shown to staff nurses of the experimental group.

\section{Method of Data Collection}

Informed written consent was taken from the samples and permission to conduct the study was obtained from the authorities.

The data was collected in the following phases.

Phase 1: The structured questionnaire consisting of 30 items was administered to the staff nurses of experimental and control group to assess the pre-test knowledge score on Lamaze breathing exercises during the first stage of labour.

Phase 2: Video-assisted teaching session of 45 minutes duration was carried out on staff nurses of the experimental group while the control group continued with the normal routine of the hospital.

Phase 3: The same questionnaire was administered on the seventh day for both experimental and control group.

\section{Plan for Data Analysis}

The plan for data analysis was as follows:
- The organization of data and information was conveyed in frequency and percentage

- The knowledge on Lamaze breathing exercises during the first stage of labour to improve maternal and foetal outcome among primi parturient mothers, analysed in terms of frequency, percentage, mean, standard deviation and t-test

- Unpaired t-test was used to compare means of the experimental and control group to test the significant difference in the knowledge between the groups

\section{Result}

\section{Demographic Variables of the Staff Nurses}

It is observed from the result as shown in Table 1, that in the experimental group, a majority of staff nurses (13 $(43.33 \%))$ belonged to $21-25$ years of age, 12 (40\%) were between $26-30$ years of age, and 5 (16.66\%) staff nurses belonged to 31-35 years of age group. In the control group, a majority of staff nurses (18 (60\%)) belonged to $21-25$ years of age, 10 (33.33\%) were between $26-30$ years of age and 2 $(6.66 \%)$ staff nurses belonged to $31-35$ years of age group.

Table I.Frequency and Percentage Distribution of Subjects as per Age, Religion, Professional Experience in years, Educational Qualification, Socio-Economic Status, and Source of Knowledge

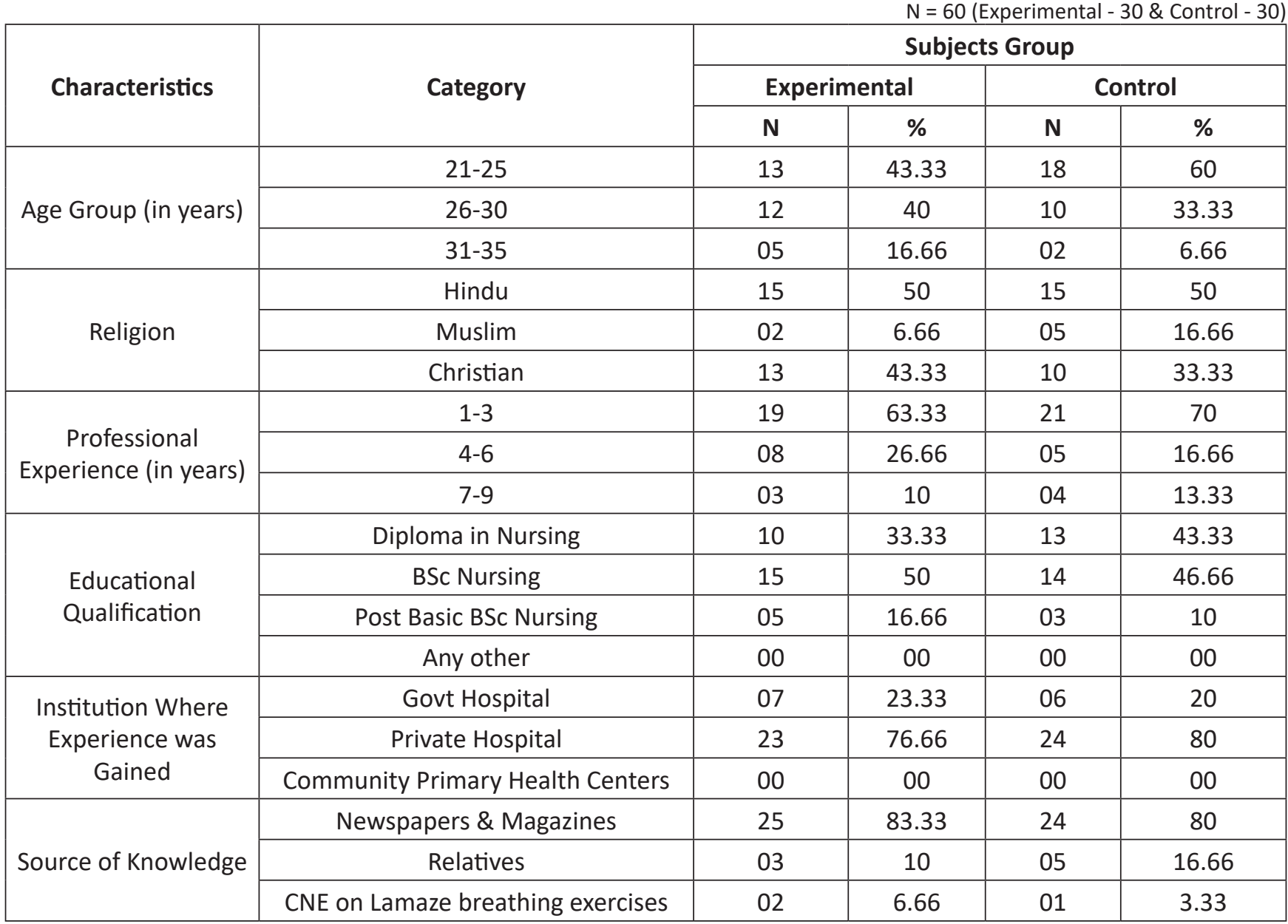


A majority of staff nurses (15 (50\%)) were Hindu, 2 (6.66\%) staff nurses were Muslim, and 13 (43.33\%) staff nurses were Christian in the experimental group. In the control group, majority of the staff nurses (15 (50\%)) were Hindu, 5 (16.66\%) were Muslim, and 10 (33.33\%) were Christian.

In the experimental group, a majority of the staff nurses (19 $(63.33 \%))$ had $1-3$ years of professional experience, 8 (26.66\%) staff nurses had 4-6 years of experience, and 3 (10\%) staff nurses had 7-9 years of professional experience. In the control group, majority of the staff nurses (21 (70\%)) had $1-3$ years of professional experience, 5 (16.66\%) staff nurses had 4-6 years of professional experience, and $4(13.33 \%)$ staff nurses had $7-9$ years of professional experience.

On analysing the educational qualification, it was found that majority of the staff nurses (10 (33.33\%)) were Diploma in nursing, 15 (50\%) were BSc Nursing, and 5 (16.66\%) were Post basic BSc Nursing in the experimental group. In control group, majority of the staff nurses (13 (43.33\%)) were Diploma in Nursing, 14 (46.66\%) staff nurses were BSc Nursing and 3 (10\%) were Post basic BSc Nursing.

Regarding the institution where the experience was gained, majority of the staff nurses $(23(76.66 \%))$ were trained in private hospitals and 7 (23.33\%) staff nurses were trained in government hospitals in the experimental group, and in the control group, 6 (20\%) staff nurses were trained from government hospital and a majority of staff nurses (24 (80\%)) were trained in private hospitals.

The source of knowledge for a majority of staff nurses $25(83.33 \%)$ was newspapers and magazines in the experimental group, $3(10 \%)$ got to know about Lamaze breathing exercises from their relatives and 2 (6.66\%) from CNE. In the control group, 24 (80\%) staff nurses acquired knowledge on Lamaze breathing exercises from newspapers and magazines, 5 (16.66\%) from their relatives, and 1 (3.33\%) from CNE.

With regards to the experimental group, a majority (24 $(80 \%))$ of the staff nurses had inadequate knowledge and $6(20 \%)$ had moderate knowledge in the pre-test but in the post-test, 4 (13.33\%) staff nurses had moderate knowledge and 26 (86.66\%) had adequate knowledge.

With regards to the control group, a majority (23 (76.66\%)) of the staff nurses had inadequate knowledge and 7 (23.33\%) had moderate knowledge in the pre-test. In the post-test 21 (70\%) had inadequate knowledge and 9 (30\%) had moderate knowledge.

Table 2.Frequency and Percentage Distribution of Overall Knowledge Score of Experimental and Control Group

$\mathrm{N}=60$ (Experimental -30 \& Control - 30)

\begin{tabular}{|c|c|c|c|c|c|c|c|c|c|}
\hline \multirow{3}{*}{ S. No. } & \multirow{3}{*}{ Level of Knowledge } & \multicolumn{4}{|c|}{ Experimental Group } & \multicolumn{4}{|c|}{ Control Group } \\
\hline & & \multicolumn{2}{|c|}{ Pre-test } & \multicolumn{2}{|c|}{ Post-test } & \multicolumn{2}{|c|}{ Pre-test } & \multicolumn{2}{|c|}{ Post-test } \\
\hline & & $f$ & $\%$ & $f$ & $\%$ & $f$ & $\%$ & $f$ & $\%$ \\
\hline 1. & Inadequate $(<50 \%)$ & 24 & 80 & - & - & 23 & 76.66 & 21 & 70 \\
\hline 2. & Moderate (51-75\%) & 06 & 20 & 04 & 13.33 & 07 & 23.33 & 09 & 30 \\
\hline 3. & Adequate (> 75\%) & - & - & 26 & 86.66 & - & - & - & - \\
\hline
\end{tabular}

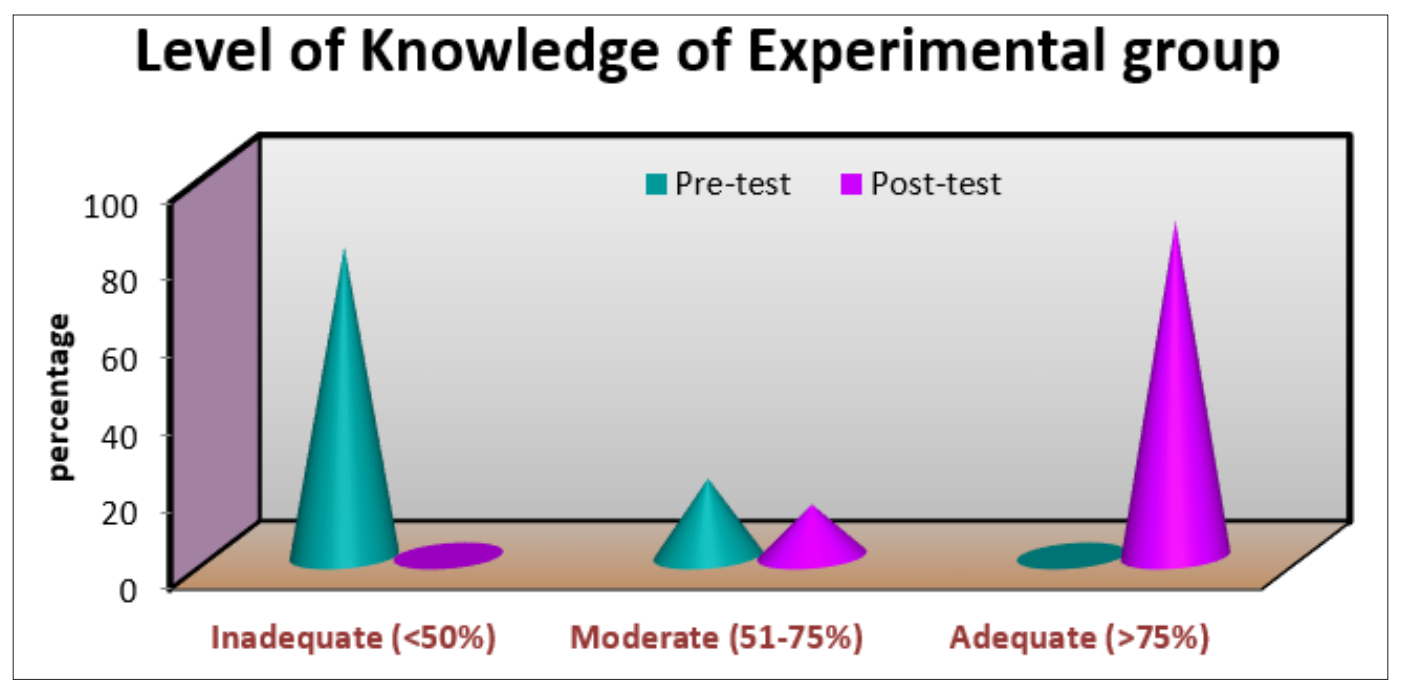

Figure I.Level of Knowledge of the Experimental Group 


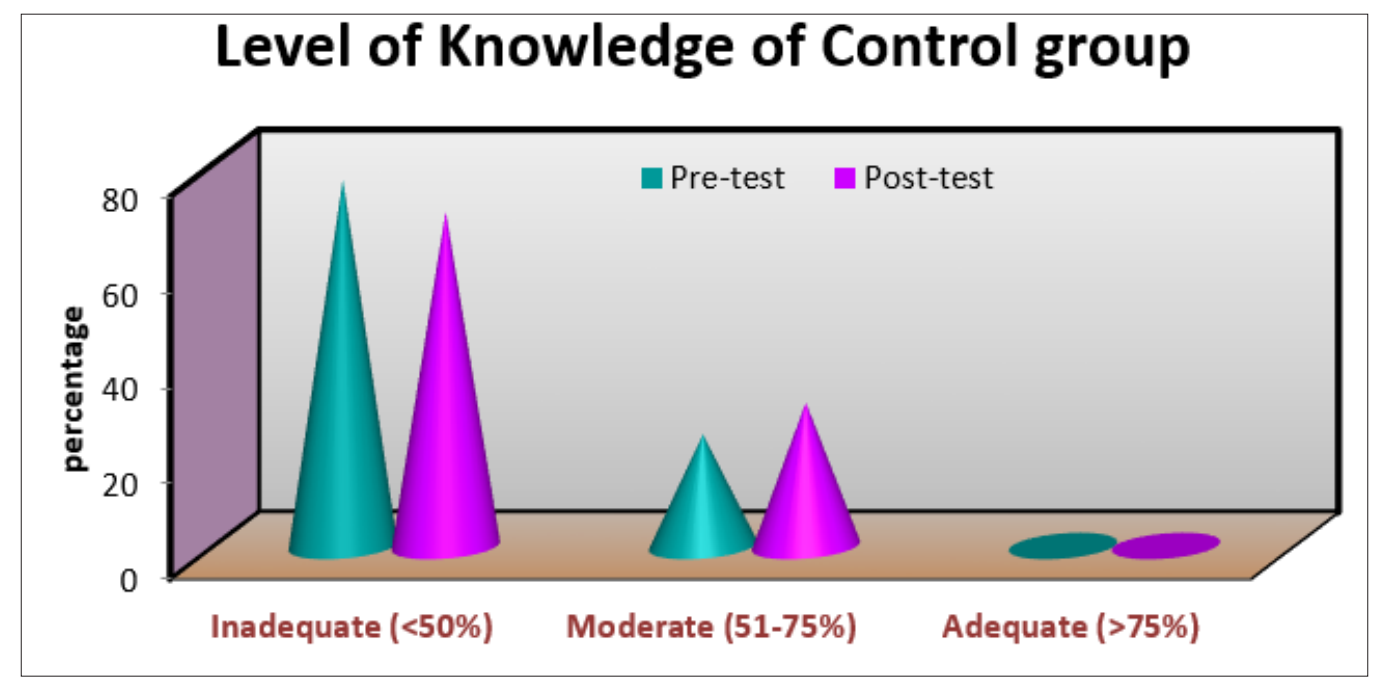

Figure 2.Level of Knowledge of the Control Group

\section{Assessment of Knowledge Score}

Association of Post-test Knowledge of Experimental and Control Group with Selected Demographic Variables

Association of post-test knowledge of experimental and control group with their selected demographic variables was analysed using chi-square test. Out of many variables for the association, age, experience, and the training institutes were associated with the contribution towards knowledge.

Table 3.Comparison of Overall Pre-Test and Post-Test Mean, Standard Deviation, Mean

Difference and Paired -'T' Value between Experimental and Control Group

$\mathrm{N}=60$ (Experimental -30 \& Control - 30)

\begin{tabular}{|c|c|c|c|c|c|c|c|}
\hline \multirow{2}{*}{ S. No. } & \multirow{2}{*}{ Group } & \multicolumn{2}{|c|}{ Mean } & \multicolumn{2}{|c|}{ Standard deviation } & \multirow{2}{*}{$\begin{array}{c}\text { Mean } \\
\text { Difference }\end{array}$} & \multirow{2}{*}{ Paired $\mathrm{t}$-Test } \\
\hline & & Pre-test & Post-test & Pre-test & Post-test & & \\
\hline 1. & Experimental & 11.712 & 22.122 & 1.2332 & 1.6 & 10.41 & $1.2 \mathrm{df}-29$ \\
\hline 2. & Control & 11.714 & 12.721 & 1.4 & 1.3 & 1.007 & $0.46818 d f-29$ \\
\hline
\end{tabular}

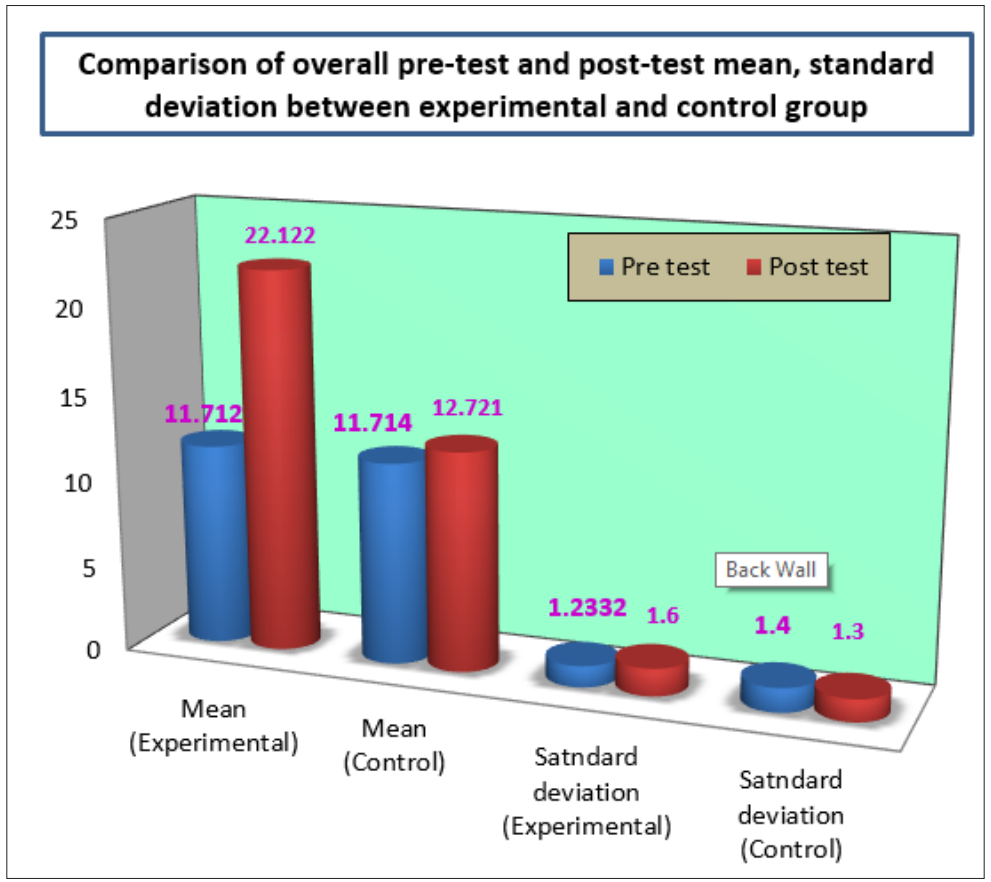

Figure 3.Comparison of Overall Pre-test and Post-test Mean and Standard Deviation between Experimental and Control Group 


\section{Discussion}

The overall percentage of knowledge in the experimental group for the pre-test was insufficient, i.e., $80 \%$ of the staff nurses, and the amount of knowledge score was moderate in $20 \%$ of staff nurses; however, after videoassisted teaching, the post-test knowledge score improved to $13.33 \%$ as moderate knowledge, and $86.66 \%$ of staff nurses demonstrated the knowledge score. Table 3 shows that the experimental group's post-test mean was 22.122 with a standard deviation of 1.6, while the control group's post-test mean was 12.721 with a standard deviation of 1.3. The $t$ value obtained is 1.2 . The null hypothesis is dismissed since the Calculated Value (CV) is greater than the Table Value (TV) at the 0.005 levels and at 29 degrees of freedom, implying that there is a substantial difference, whereas in the pre-test of the control group, $76.66 \%$ of the staff nurses had inadequate knowledge, $23.33 \%$ had moderate knowledge. In the post-test of the control group, $70 \%$ of the staff nurses had inadequate knowledge, and $30 \%$ had moderate knowledge.

\section{Conclusion}

The study showed that the knowledge score on Lamaze breathing exercises during the first stage of labour had increased after video-assisted teaching on the subject. Hence we should include video-assisted teaching to promote knowledge on the subject among staff nurses.

\section{Recommendations and Nursing Implications}

- The study can be done with larger samples for better generalization.

- Similar studies can be conducted in other settings also.

\section{Nursing Practice}

Lamaze breathing exercises are useful in controlling pain without harm to the mother, foetus or labour progress, therefore they should be utilized in the practice to improve maternal and foetal outcomes.

\section{Nursing Administration}

The nurse administrator should organize in-service education and training programs on Lamaze breathing exercises during the first stage of labour. It will improve the knowledge of staff nurses and promote comfort for labouring women besides minimizing the complications.

\section{Confidentiality of Data}

The feedback forms obtained from staff nurses were kept confidentially. Only the principal investigator has the access to these documents.

\section{Source of Funding: Self \\ Conflict of Interest: None}

\section{References}

1. Adams S, Eberhard-Gran M, Eskild A. Fear of childbirth and duration of labour: a study of 2206 women with intended vaginal delivery. BJOG 2012; 119(10): 123846. [PubMed] [Google Scholar]

2. Afari F, Khodakarami N. Guidelines of preparness classes for delivery. Ministry of Health and Medical Education, 2004.

3. Moncy A. Effectiveness of Lamaze Technique on Pain and Anxiety of Primi Gravida Mothers During 1st Stage of Labour. Indian Journal of Nursing Studies 2014; 5(1).

4. Iw A, Wijma B, Wijma K. Acta Obstetricia Gynecologica Scandinavica. 2010; 85(1).

5. Badakhsh MH, Seifoddin M, Khodakarami N, Gholami $\mathrm{R}, \mathrm{Moghimi} \mathrm{S}$. Rise in cesarean section rate over a 30year period in a public hospital in Tehran, Iran. Arch Iran Med 2012; 15(1): 4-7. [PubMed] [Google Scholar]

6. Cheung W, Chan D. Maternal anxiety and feeling of control during Labour. Journal of Obstetric and Gynecological Department 2007; 23(23): 123-30. 